\title{
LA REFORMA CONSTITUCIONAL EN BOLIVIA
}

\author{
CARLOS VIDAL PRADO \\ Profesor Asociado del Departamento \\ de Derecho Constitucional de la UNED
}




\section{SUMARIO}

1. Introducción. 2. Breve referencia histórica. 3. El procedimiento de reforma CONSTITUCIONAL. A) La supremacía de la Constitución. B) La reforma constitucional. 4. LA REFORMA DE 1994: LeY DECLARATIVA DE LA NECESIDAD DE LA Reforma y LA Ley de Reforma de 1994. A) Omisión de las modificaciones previstas inicialmente en el procedimiento de reforma constitucional. B) Cambio del sistema electoral de la Cámara de Diputados. C) Modificaciones en el sistema de elección presidencial. D) Diferencias importantes en lo que se refiere al régimen de descentralización. E) Diferente concepción del Tribunal Constitucional. F) Distinto método de elección y modificaciones en las funciones del Tribunal Constitucional. G) Modelos distintos del Consejo de la Judicatura. H) Cambios relativos al Ministerio Público. I) Modificaciones en la regulación del Defensor del Pueblo. J) Cambios en relación con el Poder Judicial. K) Otros cambios. 5. LAS LEYES INTERPRETATIVAS: ¿REFORMAS ENCUBIERTAS? 6. EL TRIBUNAL Constitucional. A) Composición y designación de los miembros del Tribunal. B) Atribuciones del Tribunal Constitucional. 7. LOS DERECHOS FUNDAMENTALES Y EL RECURSO DE AMPARO. 


\title{
LA REFORMA CONSTITUCIONAL EN BOLIVIA
}

\author{
POR \\ CARLOS VIDAL PRADO \\ Profesor Asociado del Departamento \\ de Derecho Constitucional de la UNED
}

\section{INTRODUCCIÓN}

Hace pocos años se llevó a cabo una Reforma Constitucional en Bolivia, que en muy poco tiempo ya comenzó a ser cuestionada. El proceso de reforma, como veremos en este trabajo, no se desarrolló precisamente de modo ordenado, $y$ al final, el resultado no fue, ni mucho menos, el apetecido. Esta realidad ha sido claramente asumida por la sociedad boliviana, $y$ se ha iniciado de nuevo un proceso de debate nacional sobre las necesarias reformas estructurales de un Estado que no acaba de despegar y lograr resultados políticos y económicos satisfactorios. Junto a sustanciales avances en la política de persecución del narcotráfico, hay retos importantes que deben acometerse por los políticos y la sociedad boliviana en general en los próximos años. Uno de los procesos de discusión de las reformas se enmarcó en una iniciativa denominada Diálogo 2000, que, entre otros objetivos de cambio en el ámbito económico, social y político, tiene también el de una nueva Reforma Constitucional.

En algunos aspectos, el Diálogo 2000 pudo considerarse un magnífico ejemplo de fomento de la participación de la sociedad civil. Se trataba también de un reconocimiento implícito de la insuficiencia de los habituales mecanismos de representación política. La puesta en marcha de iniciativas como ésta en Bolivia reconocía las carencias de 
un sistema de representación que no puede verse encorsetado por la actividad de los partidos politicos.

En este mismo sentido, el Diálogo 2000 perdería toda su virtualidad si, finalmente, no se estableciesen los mecanismos necesarios para que las conclusiones surgidas de este foro ciudadano sean estudiadas o asumidas por el Parlamento. Hay numerosos ejemplos en el reciente pasado boliviano de propuestas de reforma constitucional que acabaron perdidas en un cajón de despacho, y que no llegaron a plantearse siquiera en sede parlamentaria, por la cerrazón de los partidos políticos. El proceso de diálogo con todos los sectores sociales bolivianos es muy positivo, pero si al final no se traduce en la asunción por parte de los poderes públicos de las propuestas ciudadanas, todo habrá quedado en un mera operación demagógica, para hacer creer a los ciudadanos que se cuenta con ellos.

Creo que puede afirmarse que, desde el punto de vista social, y especialmente entre los juristas, se percibe la necesidad de afrontar una reforma constitucional seria, que no sea una mera modificación circunstancial, como algunas de las que se han hecho hasta ahora. Sin embargo, esta necesidad no es asumida de igual manera por la clase política, más preocupada por conservar sus privilegios que por llevar a cabo lo que más interesa al país.

La Constitución boliviana puede ser mejorada en muchos aspectos. Además de cambios en su contenido, deberian acometerse también modificaciones en su orden sistemático. No tiene sentido, por ejemplo, que encontremos derechos fundamentales dispersos por todo el texto constitucional. Lo lógico sería que se agrupasen en un mismo apartado, y que se estableciese un sistema de garantías específico para cada uno de ellos, en función de su ubicación en la Constitución. Los especialistas bolivianos admiten la conveniencia y necesidad de esta reforma, pero a continuación suelen señalar que los partidos políticos no quieren acometerla, para evitar la apariencia de una reforma total. No creo que esta sea la vía adecuada para resolver los problemas.

Si la Constitución de un país quiere mantener plenamente su vigencia, necesita ser periódicamente reformada, para adaptarse a los nuevos tiempos. Y si la reforma que se requiere es importante, los políticos deben tener el coraje suficiente de afrontarla con todas sus consecuencias. Una reforma raquítica no soluciona nada, y hará necesarios nuevos cambios en poco tiempo. Esta labor debe realizarse con amplitud de miras, anteponiendo los intereses del país a los del partido, para que de verdad se obtengan los frutos deseados. 
La reforma de la Constitución es un instrumento necesario para que la Norma Suprema de un Estado mantenga su vigencia efectiva y la supremacía en el marco de la pirámide normativa. Debe huirse tanto de la utilización excesivamente frecuente de la reforma como del rechazo a la misma. Pero si no se acomete una reforma profunda y meditada, que sea producto de una reflexión sincera y de un intercambio de distintas opiniones con el ánimo de llegar a acuerdos, entonces esa modificación constitucional acabará siendo, en la práctica, insuficiente, y al cabo de poco tiempo la sociedad volverá a reclamar una nueva reforma.

Si no me equivoco, puede decirse que algo así ocurrió en Bolivia, como acertadamente ha señalado Urenda', con la última reforma constitucional, por lo que se refiere, entre otras cosas, a la descentralización y a la modificación de los artículos 109 y 110 de la Constitución. Sin duda ésta sería una de las medidas necesarias para solucionar los desequilibrios territoriales de Bolivia, puesto que se estaría afrontando el problema desde el punto de vista estructural. Sin embargo, el modo como se aprobó la definitiva redacción de estos artículos fue un ejemplo claro de lo que no tiene que ser una verdadera reforma constitucional. En un debate parlamentario en el cual no se actuó precisamente pensando en el bien del país, sino en el de algunos oligarcas políticos, se frustró lo que toda una movilización ciudadana había conseguido a lo largo de mucho tiempo. Esto es lo que no debería volver a ocurrir.

Partiendo de estas premisas, pretendo en este trabajo analizar algunos apartados de la Constitución de Bolivia que me parece deben ser reformados, comenzando por el mismo procedimiento de reforma, que, en mi opinión, adolece de varios defectos. Haré una referencia inicial a la historia constitucional boliviana, para luego ir entrando en el análisis de la última reforma, y en aspectos concretos de la vigente Constitución que, en mi opinión, podrían revisarse, bien en cuanto a su contenido, bien en cuanto a su sistematización.

\section{BREVE REFERENCIA HISTÓRICA}

Miguel Harb sostiene que en Bolivia sólo ha habido una Constitución, la enviada por Simón Bolivar y promulgada por la Asamblea Conspágs. 59 y ss.

URENDA DiAz, J.C., La descentralización deficiente, Santa Cruz, 1999, 
tituyente el 19 de noviembre de 1826, y que posteriormente fue reformada en 17 oportunidades ${ }^{2}$. Algo parecido había dicho Félix Trigo en 1957, considerando que, si bien por entonces habian existido ya catorce constituciones bolivianas, un análisis de los textos constitucionales permitía sostener que no se trataba de distintas constituciones, sino que había existido unidad y continuidad histórica entre todas ellas ${ }^{3}$.

Sin embargo, ofrece muchas dudas esta afirmación. Quizá en sentido material podría sostenerse que en todos los textos constitucionales se han mantenido algunos elementos invariados, pero en ningún caso desde el punto de vista formal es defendible esta postura, pues sólo en contadas ocasiones se han respetado los procedimientos de reforma ${ }^{4}$.

Según Miguel Harb, se ha conservado la parte dogmática, la forma de la Jefatura del Estado (republicana), la organización unitaria y la división de poderes. Si así fuese, podría hablarse del mantenimiento de los elementos esenciales de la Constitución en sentido material. Pero, formalmente, como ha dicho Dermizaky, la Constitución boliviana uha sido reformada muchas veces al margen del procedimiento que la misma señala, al calor de las improvisaciones de los gobiernos de facto, cuyos titulares, en su afán de justificar la captura del poder, han convocado frecuentemente a asambleas constituyentes (no previstas en nuestro régimen constitucional), para legitimar su gestión y reformar la ley fundamental ${ }^{5}$.

El mismo Miguel Harb reconoce que la única reforma que se ha llevado a cabo siguiendo el procedimiento previsto (aunque en este caso es también muy discutible, por las muchas irregularidades que se cometieron) fue la de 1994. "Las demás han sido hechas -dice- en las mal llamadas constituyentes o convenciones nacionales convocadas por gobiernos de facto" ${ }^{6}$. Además, siguieron el procedimiento de refor-

2 Miguel HARB, B., "La jurisdicción constitucional en Bolivia", en Fernández Segado, F. (coord.), La jurisdicción constitucional en Iberoamérica, Dykinson, Madrid, 1998, pág. 337.

3 FÉLIX TrIGo, F., "Estudio Preliminar" a su obra Las Constituciones de Bolivia, Instituto de Estudios Políticos, Madrid, 1958, pág. 61.

$4 \quad$ Las distintas constituciones, sin incluir la actual, pueden consultarse en Salinas Mariaca, R., Compilación de las Constituciones Bolivianas, Talleres Escuelas de Artes Gráficas del Colegio Don Bosco, 2. Edición, La Paz, 1989.

5 Dermizaky Peredo, P., Derecho Constitucional, Cochabamba, Bolivia, 1996, pág. 52.

6 Miguel HaRB, B., "La jurisdicción constitucional en Bolivia», en FerNÁndez Segado, F. (coord.), La jurisdicción constitucional en lberoamérica, op. cit., pág. 340. 
ma previsto en la Constitución las modificaciones que se realizaron por medio de las siguientes leyes: Ley de 1905, reformando el artículo 2 de la Constitución de 1880 sobre libertad de cultos; Ley de 16 de noviembre de 1942, que modifica el artículo 112 de la Constitución de 1938, sobre elaboración de Presupuestos por el Legislativo; Ley de 30 de septiembre de 1947 y Ley de 27 de noviembre de 1947, que reforman varios artículos de la Constitución de 1945.

Las citadas en el párrafo anterior son las únicas reformas que podrian considerarse formalmente como tales. Las demás son, desde el punto de vista formal, Constituciones diferentes a las anteriores.

Pero incluso desde el punto de vista material ofrece dudas importantes la consideración de que ha existido una sola Constitución boliviana. Si tenemos en cuenta que bajo los llamados gobiernos de facto no se respetaron muchas de las previsiones incluidas en la Constitución (entre otras, cuestiones tan importantes como la división de poderes o las garantías de los derechos), no puede hablarse tampoco de que haya existido una misma Constitución, puesto que en muchos casos ésta era meramente nominal o semántica, siguiendo la terminologia de Loewenstein. Además, la parte dogmática, es decir, los derechos fundamentales y sus garantías, no se incluyen hasta la Constitución de 1851 (la sexta cronológicamente), por lo tanto no es cierto que esta parte se mantenga desde el inicio. En cuanto al diseño organizativo del Estado, cambia radicalmente en 1880, con el principio de descentralización. Otra cosa es que no se haya ejecutado este principio hasta la aprobación de la Ley de Descentralización administrativa, en fechas muy recientes.

\section{EL PROCEDIMIENTO DE REFORMA CONSTITUCIONAL}

En primer lugar, el análisis del propio procedimiento de reforma de la Constitución arroja ya unas conclusiones claras. Pienso que la regulación constitucional es deficiente, y que deben revisarse algunos de los contenidos de los artículos correspondientes.

\section{A) La supremacía de la Constitución}

La reforma constitucional está regulada en los artículos 230 a 233 de la Constitución boliviana. Dos artículos previos, el 228 y 229 , pretenden afirmar la primacía de la Constitución, en un sistema jurídico en 
el cual no todos los operadores la tienen clara, o al menos no lo han demostrado con su labor, hasta el comienzo de las actuaciones del Tribunal Constitucional boliviano, en julio de 1999.

El artículo 228 supone una declaración formal de la supremacía constitucional, que vincula a tribunales, jueces $y$ autoridades, que deben aplicar la Norma Suprema con preferencia a las leyes. Además, se hace una alusión al principio de jerarquia normativa, cuando se dice que las leyes deberán ser aplicadas «con preferencia a cualesquiera otras resoluciones".

Ofrece aristas más problemáticas el siguiente artículo (229). Éste dice así: "Los principios, garantías y derechos reconocidos por esta Constitución no pueden ser alterados por las leyes que regulen su ejercicio ni necesitan de reglamentación previa para su cumplimiento". El primer inciso del artículo pretende constituirse en la garantía del contenido esencial no sólo de los derechos, sino de las garantías y los principios reconocidos en la Constitución.

Una primera cuestión que se plantea es cómo puede saberse que un principio constitucional está siendo alterado. En la base de todo ordenamiento jurídico existen unos valores, y a su vez de este Ordenamiento podemos extraer sus principios fundamentales, "principios técnico-jurídicos que sirven de malla a esa estructura un tanto vaporosa de los valores y el Ordenamiento jurídico considerado como un todo" ${ }^{7}$. Los principios suponen el fundamento del propio texto constitucional, pero no suelen estar positivados como tales. Por tanto, mientras que los derechos y garantías pueden ofrecer un punto de referencia objetivo y positivo para valorar su posible vulneración, no ocurre lo mismo en el caso de los principios.

Desde el punto de vista teórico, la concreción de esos principios deberá realizarse a través de la interpretación jurisprudencial de la Constitución, tanto de los tribunales ordinarios como del Tribunal Constitucional. En un sistema como el boliviano, en el cual los tribunales ordinarios no están todavia muy habituados a aplicar e interpretar la Constitución, probablemente tendrá que ser el Tribunal Constitucional (como ya ha ocurrido en este corto espacio de tiempo que lleva

7 Torres del Moral, A., Principios de Derecho Constitucional español, Servicio de Publicaciones de la Universidad Complutense, 4. Edición, Madrid, 1998, pág. 52. Sobre los conceptos de valores y principios, pueden verse los libros de Peces Barba, G., Los valores superiores, Madrid, 1984, y Pérez LuÑo, A.E., Derechos humanos, Estado de Derecho y Constitución, Madrid, 1984. 
actuando) quien determine esa posible violación de un principio constitucional, realizando una labor, si así puede decirse, pedagógica con respecto a los jueces ordinarios.

El mismo problema se plantea, con referencia a los principios, a la hora de analizar el último inciso de este artículo, es decir, el que dice que no necesitan de reglamentación previa para su cumplimiento. Si un principio no está positivado en la Constitución, ¿cómo puede ser directamente aplicable sin un desarrollo normativo posterior que lo concrete? Pienso que, de nuevo en este caso, será el Tribunal Constitucional quien, como intérprete supremo de la Constitución, aporte en su jurisprudencia la concreción necesaria.

Podría objetarse también a este artículo un cierta contradicción con el artículo 7 de la Constitución, que relaciona una serie de derechos fundamentales, que "toda persona" posee, "conforme a las leyes que reglamenten su ejercicio". Parece que aquí se exige una ley que reglamente el ejercicio de los derechos para poder reclamarlos, mientras que en el artículo 229 se afirma que los derechos no necesitarán reglamentación previa para su cumplimiento. Pienso que no se trata de una contradicción, sino de la afirmación, en este último caso, de la normatividad de la Constitución, es decir, de la eficacia normativa directa de los derechos fundamentales, mientras que en el artículo 7 se prevé la remisión a una ley de la regulación concreta de cada derecho, pero ello no implica que, mientras no exista esa regulación, no puedan los ciudadanos acogerse a ese derecho. Lo que sí puede achacarse a estos dos preceptos es la utilización no excesivamente rigurosa del término "reglamentar", puesto que puede dar lugar a confusiones, al no especificar si se refiere a desarrollo legislativo o reglamentario.

\section{B) La reforma constitucional}

Por lo que se refiere a los artículos que regulan especificamente la reforma constitucional, el primero de ellos es el 230, que se transcribe a continuación:

il. Esta Constitución puede ser parcialmente reformada, previa declaración de la necesidad de reforma, la que se determinará con precisión en una ley ordinaria aprobada por dos tercios de los miembros presentes en cada una de las Cámaras.

II. Esta ley puede ser iniciada en cualquiera de las Cámaras en la forma establecida por esta Constitución. 
III. La ley declaratoria de la reforma será enviada al Ejecutivo para su promulgación, sin que Éste pueda vetarlan.

La lectura de este artículo presenta varios aspectos problemáticos:

a) En primer lugar, no se define en qué consiste la reforma parcial, para distinguirla de la total. No se hace tampoco alusión a si se trata de una parcialidad en sentido cualitativo o cuantitativo. Al no concretarse el contenido del término "parcialmente", no habría ningún obstáculo para calificar de parcial a una reforma de todos los artículos de la Constitución menos uno, por ejemplo el 235, que incluye la cláusula derogatoria habitual.

Miguel Harb sostiene que el término parcial debe entenderse en el sentido de que "la parte dogmática, que está titulada como Disposiciones Generales, no puede ser reformada contra la estructura y esencia de las características del Estado boliviano, como así también no pueden disminuirse y limitarse los derechos y garantías de las personas (artículos 1 al 35 inclusive) 18 . Pero esto no deja de ser una opinión doctrinal, que no se basa en ningún argumento jurídico-positivo, y que no viene a solucionar el problema, puesto que podrian considerarse también como esenciales otros apartados de la Constitución.

Es evidente, por tanto, la necesidad de concretar esta parcialidad, y quizá la vía adecuada sea la de señalar, como se hace en la Constitución española de 1978, aquellos apartados de la Constitución cuya reforma llevaría consigo el calificativo de parcial y aquéllos que supondrian una reforma total, por afectar a elementos básicos del sistema político boliviano, como la forma de gobierno republicana.

b) En segundo lugar, en este artículo se dispone que el primer paso de una reforma constitucional debe ser la aprobación de la Ley de necesidad de reforma. Se trata de una declaración que debe revestir la forma de ley ordinaria, y que tendrá que aprobarse por los "dos tercios de los miembros presentes en cada una de las Cámaras".

8 Miguel HarB, B., "La jurisdicción constitucional en Bolivia", en Fernández Segado, F. (coord.), La jurisdicción constitucional en lberoamérica, op. cit., pág. 351. 
Aquí surgen varios puntos conflictivos: por un lado, no se aclara si la declaración de necesidad es simplemente eso, o también debe contener los aspectos concretos de la reforma constitucional, o incluso la previsión de artículos a reformar, con el nuevo texto que se le quiere dar a los mismos. Por otro lado, la mayoría establecida es bastante peculiar. Al disponer que los dos tercios se contarán en relación con los miembros presentes en la Cámara, podría ocurrir que una ley de necesidad de reforma fuese aprobada por el escaso número de 44 diputados o sólo 9 senadores ${ }^{9}$. Lo que debería decir ese artículo es que la mayoría requerida es la de dos tercios del total de diputados o senadores, porque si no la reforma se convertiría en un instrumento que, más que estabilidad, podría aportar lo contrario si se utiliza de modo irresponsable. Las mayorías reforzadas sólo tienen sentido si sirven como garantía, y en este caso no lo hacen.

Los otros dos apartados del artículo no ofrecen aparentemente ningún inconveniente. Por un lado, se dispone que la iniciativa de la declaración de necesidad de la reforma (en este apartado se le denomina directamente como "ley") puede producirse indistintamente en las dos Cámaras. Por otro, se dice que la "ley declaratoria" (se cambia la denominación de nuevo) no podrá ser vetada por el Ejecutivo. Si acaso, lo que puede reprocharse otra vez a estos dos apartados es la escasa rigurosidad del empleo del lenguaje técnico jurídico. Debería de unificarse la denominación, y hablar quizá desde el principio de "ley de declaración de necesidad de la reforma constitucional".

El siguiente artículo, el 231, establece lo siguiente:

«I. En las primeras Sesiones de la Legislatura de un nuevo periodo constitucional se considerará el asunto por la Cámara que proyectó la reforma $y$, si ésta fuere aprobada por dos tercios de votos, se pasaran a la otra para su revisión, la que también requerirá dos tercios.

II. Los demás trámites serán los mismos que la Constitución señala para relaciones entre las dos Cámaras".

Al leer el primer epígrafe de este artículo podría pensarse que se está dando por supuesta una disolución de las Cámaras tras la apro-

9 El artículo 48 de la Constitución establece un quórum para las reuniones de las dos Cámaras que componen el Congreso boliviano (de Diputados y de Senadores) de la mayoría absoluta. El número total de diputados es de 130 , y el de senadores es de 3 por Departamento (27). Si se tienen en cuenta las cifras mínimas para el quórum, y sobre ellas se aplica la mayoria de dos tercios, se obtienen los resultados indicados en el texto. 
bación de la ley de necesidad de la reforma constitucional. Pero no se hace de modo expreso y, por lo tanto, el artículo debe interpretarse -y así se ha venido haciendo en la práctica política boliviana- en el sentido de que, una vez aprobada la ley, las Cámaras deben esperar a la extinción jurídica de su mandato representativo, es decir, que se debe esperar a la disolución automática del Congreso por el paso del tiempo para el cual ha sido elegido.

Llama la atención esta disposición, puesto que, si se aprueba la necesidad de una reforma constitucional, no tiene sentido esperar al momento de la disolución natural de las Cámaras. Si la reforma es necesaria, no debería de aplazarse, a través de una especie de "congelamiento" de la misma. Lo que parece más oportuno es la disolución anticipada de las Cámaras, para que, tras unas nuevas elecciones, las nuevas Cámaras puedan pronunciarse de nuevo sobre los términos de la reforma que, probablemente, serán el centro de la campaña electoral. Al menos, debería preverse este mecanismo para aquellos casos en que la reforma se considere más urgente.

Las deficiencias técnicas de este artículo son también sorprendentes: en el primer párrafo se exige que la Cámara que "proyectó la reforma" considere el "asunto", y si "ésta" (la reforma) fuere aprobada por "dos tercios de los votos" pasará a la otra Cámara para su "revisión", que también requerirá "dos tercios». Veamos con detalle las necesarias modificaciones de este texto:

a) Se habla de la Cámara que "proyectó la reforma». Hasta ahora, de lo único que se había hablado en la Constitución es de la declaración de necesidad de la reforma, pero no de un proyecto de reforma. La redacción del artículo 231 parece dar por supuesto que, en la ley de declaración de la necesidad, se debe incluir ya el proyecto. Debería coordinarse la redacción de ambos artículos.

b) No parece que la redacción (considerar el «asunto») sea la más afortunada desde el punto de vista técnico-jurídico.

c) Se habla de que la Cámara que llevó la iniciativa en el proceso de reforma constitucional debe aprobarla de nuevo "por dos tercios de votos". ¿A qué votos se refiere? ¿A los emitidos, es decir, dos tercios de los miembros presentes? ¿O quizá se refiere al total de miembros? Sin duda, la laguna en este caso debe ser subsanada para evitar situaciones de inseguridad jurídica. El criterio, en mi opinión, debería ser el que se utiliza en la gran mayoría de las constituciones: debe tenerse 
en cuenta el número total de miembros, no sólo el de los presentes.

d) Por último, se habla de que el proyecto de reforma pasará a la otra Cámara "para su revisión". No se sabe en qué consiste la revisión. ¿Es un sinónimo de aprobación? No parece. ¿Quiere decir que, en todo caso, la segunda Cámara debe introducir alguna revisión, o sea, alguna modificación? No creo que pueda establecerse dicha medida preceptiva, violando claramente la libertad de decisión de la Cámara. Debemos suponer que se trata de un error de redacción, y que en realidad se ha querido decir "aprobación», porque además, el último inciso de este apartado dice: «la que también requerirá dos tercios". No es lógico que una revisión pueda hacerse por dos tercios, sino más bien una aprobación. Lo que ocurre es que, en este caso, todavía es más llamativa la expresión «dos tercios", porque ya ni se dice si se refiere a votos, a parlamentarios... Una vez más, debe introducirse un criterio coherente y claro, en el sentido que vengo manteniendo desde hace unas líneas.

El párrafo segundo del artículo 231 remite los demás trámites del procedimiento de reforma a los habituales en las relaciones entre ambas Cámaras, es decir, a los previstos en los artículos 71 y siguientes de la Constitución.

Analicemos ahora el texto del artículo 232:

“l. Las cámaras deliberarán y votarán la reforma ajustándola a las disposiciones que determinen la ley de declaratoria de aquella.

II. La reforma sancionada pasará al Poder Ejecutivo para su promulgación, sin que el Presidente de la República pueda observarla».

El primer párrafo establece el requisito, vinculante para las Cámaras, de ajustarse a "las disposiciones que determine la ley declaratoria de ésta»(la reforma). No queda claro en el texto si se refiere a las disposiciones de tipo procedimental, o si, en caso de que la ley no sea una simple declaración, sino que contenga además un proyecto de reforma, éste vincularía también a las nuevas Cámaras.

Lo lógico sería que, si la ley es meramente declaratoria de la necesidad de la reforma, las nuevas Cámaras tengan libertad para elaborar o modificar el proyecto de reforma en aquellos aspectos que les parezca oportuno, y que sólo deban sujetarse a las disposiciones de tipo procedimental. No tendría sentido que la ley declaratoria de la reforma vinculase, en el contenido de la reforma, a las nuevas Cáma- 
ras, porque entonces, ¿para qué se espera a una nueva legislatura, o un nuevo "período constitucional", como se afirma en el art. 231?

No obstante, ésta no ha sido la interpretación que se le ha dado a la norma, sino que se ha identificado el concepto de ley de declaración con el propio proyecto de reforma, y, como consecuencia, el contenido de este proyecto debería vincular a las nuevas Cámaras. Lo que ocurre es que, como veremos en el siguiente apartado, esta previsión teórica no se ha respetado en la práctica.

El segundo apartado del artículo establece la prohibición del veto presidencial a la reforma, que debe tramitarla de modo preceptivo, y proceder a su promulgación.

Por último, el artículo 233 establece que "cuando la enmienda sea relativa al período constitucional del Presidente de la República, será cumplida sólo en el siguiente período". Se trata de un límite temporal de tipo técnico, que no ofrece ningún inconveniente y no parece problemático.

\section{LA REFORMA DE 1994: LEY DECLARATIVA DE LA NECESIDAD DE LA REFORMA Y LEY DE REFORMA DE 1994}

Con relación al contenido de la Ley declarativa de la necesidad de la reforma, Miguel Harb dice que el proyecto de Reforma Constitucional "es ley de declaratoria de necesidad de la reforma constitucional", con lo cual está identificando dos conceptos que formalmente, al menos en lo que se refiere a su denominación, no parecen ser lo mismo. Una cosa es la ley en la que se declara la necesidad de la reforma, y otra el propio proyecto de Reforma. El hecho de que en Bolivia se haya convertido en práctica habitual esa identificación no quiere decir que debamos aceptar sin más esa regulación actual. Debería aclararse en la Constitución boliviana a qué se está refiriendo con la ley declaratoria de la necesidad de la reforma, y si en ella debe incluirse o no el proyecto. En caso positivo, deberá especificarse si el texto del proyecto vincula a las nuevas Cámaras, o éstas pueden modificarlo.

Lo que dice actualmente el artículo 232 de la Constitución es que las nuevas Cámaras deben ajustarse a las disposiciones de la ley declaratoria de necesidad, $y$, por tanto, no pueden agregar ni suprimir aspectos no contemplados expresamente en dicha ley. Pero no ha ocurrido así, al menos en la última reforma de 1994. Es más, ha habido cambios sustanciales, lo cual pone en evidencia que el procedimiento de reforma actualmente previsto debe ser modificado, pues en la práctica no 
se está respetando. Como vengo sosteniendo, lo lógico sería que las nuevas Cámaras no se viesen vinculadas por la voluntad de las anteriores, pero tal como está regulado el procedimiento en la actualidad, formalmente sí lo están, aunque en la práctica no se cumpla lo previsto, lo cual podría, en mi opinión, llevar a considerar que la reforma de 1994 ha sido llevada a cabo de modo irregular, y por tanto sería formalmente anulable.

Veamos en concreto cuáles son los aspectos más relevantes de la reforma del 94 que fueron modificados en la versión definitiva del texto $^{10}$. Se trata de contrastar el texto de la Ley número 1473 , de 1 de abril de 1993, declaratoria de la necesidad de la Reforma, y la Ley número 1585, de 12 de agosto de 1994, de Reforma de la Constitución Política del Estado boliviano"1.

\section{A) Omisión de las modificaciones previstas inicialmente en el procedimiento de reforma constitucional}

Dejando al margen las numerosas correcciones de estilo o gramaticales que se incluyen en la segunda de las leyes, y que no pienso que vulneren el procedimiento de reforma previsto, lo primero que Ilama la atención es que, en la Ley de necesidad se incluye una modificación de los artículos 230,231 y 233 de la Constitución, que regulan el procedimiento de reforma, y sin embargo dicho cambio desaparece en la Ley de Reforma de 1994. Básicamente, el nuevo régimen pretendia diferenciar la reforma del Título preliminar, que se hacía más exigente, de la del resto de la Constitución.

Resulta bastante extraño que, expresando la propia Constitución la obligatoriedad de ajustarse la Reforma al texto de la Ley de necesidad, en este caso se vulnere de modo tan claro dicha disposición. El procedimiento de reforma constitucional no parece haberse respetado, al menos en este punto, y podría haber sido objeto de revisión por parte del Tribunal Constitucional, si no fuera porque éste todavía no se había constituido.

10 Un completo y temprano análisis es el de AsBún, J., Análisis juridico-político de la reforma constitucional, Universidad Privada de Santa Cruz de la Sierra, Santa Cruz, 1994

11 Pueden consultarse los textos en la Gaceta Oficial de Bolivia, n.. 1779, de 1 de abril de 1993, y Gaceta Oficial de Bolivia n.o 1842, de 12 de agosto de 1994 . 


\section{B) Cambio del sistema electoral de la Cámara de Diputados}

El artículo 60 se ha reformado de modo diferente a como estaba previsto en la ley de 1993. Así, por ejemplo, dicha ley preveía un máximo de 130 miembros para esta Cámara, mientras que el texto definitivo suprime el margen de flexibilidad y fija el número en 130 . Pero el cambio sustancial es que, mientras que en la primera Ley se establecía un sistema de elección basado en listas nacionales, en el texto definitivo todo el sistema se basa en listas departamentales.

\section{C) Modificaciones en el sistema de elección presidencial}

También el texto definitivo del artículo 87 no coincide con el inicialmente previsto. Mientras que la ley de 1993 incluía un apartado que decía: «ningún ciudadano puede ejercer la Presidencia por más de dos períodos constitucionales", éste se suprimió en la Ley de Reforma de 1994. Asimismo, mientras que en la Ley declaratoria se hablaba de repetición de la votación para elegir Presidente por tres veces en caso de empate (artículo 90), en la Ley de Reforma se reducen a dos dichas repeticiones.

\section{D) Diferencias importantes en lo que se refiere al régimen de descentralización}

La redacción de los artículos 109 y 110 de la Constitución que se preveía en la Ley de 1993 fue modificada de modo esencial en la definitiva Ley de Reforma de $1994^{12}$. Así, se suprimió en esta última el siguiente párrafo del artículo 109 incluido en el texto inicial: "Los Gobiernos Departamentales se desenvolverán de acuerdo a un Régimen de Descentralización Administrativa. La organización, el funcionamiento, y las atribuciones de los Gobiernos Departamentales se definen por Ley".

Asimismo, la figura del Prefecto departamental sufre bastantes cambios entre un texto y otro. Mientras que la ley de 1993 lo considera "representante" del Poder Ejecutivo, la de 1994 considera que el Poder Ejecutivo "está a cargo y se administra" por un Prefecto. La primera Ley atribuye al Prefecto bastantes más funciones que la segunda,

12 URENDA Diaz, J.C., La descentralización deficiente, Santa Cruz, 1999, págs. 59 y ss. 
en la que se opta por remitir la regulación concreta de estas atribuciones a una futura ley, excluyéndola, por tanto, del texto constitucional. La importancia del Prefecto se reduce también en la Ley de 1994, al añadir el siguiente párrafo al artículo 109, no previsto inicialmente: "Los Senadores y Diputados podrán ser designados Prefectos de Departamento, quedando suspensos de sus funciones parlamentarias por el tiempo que desempeñen el cargo».

Curiosa regulación ésta, que en lugar de declarar la incompatibilidad permite solicitar una especie de "excedencia" a los diputados y senadores, para ocupar temporalmente el cargo de Prefecto, con lo cual la Cámara de Diputados o el Senado ya no tendría el número previsto de representantes, sino que podría reducirse éste temporalmente. ¿Cuál se consideraría entonces el número de parlamentarios a partir del cual calcular las mayorias reforzadas?

El artículo 110 ha quedado también, en su versión definitiva, totalmente distinto a como estaba previsto en la Ley de 1993. La versión inicial era mucho más detallada, haciendo hincapié en algunas competencias departamentales que pretendían acentuar una descentralización que abortó la Ley de Reforma de 1994. Por ejemplo, la Asamblea consultiva departamental tenía la facultad de fiscalizar los actos de la Prefectura, lo cual se ha eliminado en la Ley de 1994. Es más, dicho órgano, que se llamaba exactamente Asamblea Consultiva $y$ de Fiscalización Departamental, no está siquiera previsto en el texto que finalmente se aprobó y se incluyó en la Constitución. Sólo se habla de un Consejo Departamental, cuya composición y funciones se deberán establecer a través de una ley.

En mi opinión, la creación de esta Asamblea, que debia controlar la actuación del Poder Ejecutivo departamental, es decir, la Prefectura, suponía un primer paso hacia la democratización de los poderes territoriales, que habría traído consigo un mayor peso de estas instituciones. Sin embargo, este proyecto se truncó, del mismo modo que se frustraron muchos de los propósitos descentralizadores con la versión definitiva de la Ley de descentralización administrativa que se aprobó poco tiempo más tarde.

\section{E) Diferente concepción del Tribunal Constitucional}

El artículo 121 de la Ley declaratoria decía que el Tribunal Constitucional "es independiente de los demás órganos del Estado y está sometido sólo a la Constitución». Sin embargo, el artículo 116 de la Constitu- 
ción reformada integra al Tribunal Constitucional dentro del Poder Judicial, y se suprime la referencia a los demás órganos del Estado: sólo se afirma que el Tribunal Constitucional «es independiente y está sometido sólo a la Constitución". Puesto que tribunales ordinarios y Tribunal Constitucional forman parte del Poder Judicial, la Ley de 1994 se ve obligada a introducir dos párrafos en este artículo que no figuraban en la Ley de 1993, para diferenciar bien las competencias de unos y otro ${ }^{13}$.

Esta modificación es sustancial, y pudo deberse a la polémica que originó el texto de la Ley de necesidad de la Reforma. Algunos sostuvieron que dicho texto suponía la creación de un cuarto poder, atentando contra la separación y el equilibrio entre los poderes tradicionales $^{14}$. Otros propusieron que se integrase al Tribunal Constitucional en el ámbito del Poder Judicial, aunque con absoluta independencia ${ }^{15}$. Sea cual sea la causa del cambio, éste es decisivo y poco afortunado, como se ha dicho acertadamente ${ }^{16}$.

El Tribunal Constitucional debe ser necesariamente independiente de todos los demás órganos del Estado, para poder ejercer eficazmente sus funciones, y en la actual redacción de la Constitución boliviana no sólo no es así, sino que, al formar parte del Poder Judicial, depende, a los efectos de organización y disciplinarios, del Consejo de la Judicatura, que está presidido por el presidente de la Corte Suprema, lo cual imposibilita la actuación plenamente independiente y autónoma del Tribunal Constitucional.

\section{F) Distinto método de elección y modificaciones en las funciones del Tribunal Constitucional}

En cuanto al sistema de elección de Magistrados, mientras que en la Ley de 1993 se exigían los 2/3 de los votos del total de miem-

13 Artículo 116, párrafo 3: «La facultad de juzgar en la vía ordinaria, contenciosa y contencioso-administrativa y la de hacer ejecutar lo juzgado corresponde a la Corte Suprema y a los Tribunales y jueces respectivos, bajo el principio de unidad jurisdiccional». Artículo 116, párrafo 4: «El control de constitucionalidad se ejerce por el Tribunal Constitucional".

14 Pelaez Gantier, G., "El Tribunal Constitucional y la Corte Suprema", en Presencia, La Paz, 25 de mayo de 1993.

15 Urcullo ReYes, J., Proceso democrático, situación jurídica y reforma constitucional en Bolivia, op. cit., pág. 167.

16 Fernández Segado, F., "La jurisdicción constitucional en la Reforma de la Constitución de Bolivia de 1994", en FeRnández SEgAdo (coord.), La jurisdicción constitucional en lberoamérica, op. cit., pág. 368. 
bros del Congreso (artículo 121), en el texto definitivo sólo se exigen los 2/3 de los miembros presentes (artículo 119). Estas modificaciones de las mayorías son frecuentes en la Ley de Reforma, con relación a la Ley de 1993, y, en mi opinión, restan garantías a que la elección sea verdaderamente fruto de un acuerdo lo más amplio posible de las Cámaras.

Además, la Ley de Reforma suprime una incompatibilidad que sí figuraba en la Ley declaratoria: "La condición de Magistrado del Tribunal Constitucional es incompatible con cualquier otra función pública o actividad privada". Todo lo que sea eliminar incompatibilidades supone restar elementos de garantía para la independencia de actuación del Tribunal Constitucional, por lo que no parece adecuada esta omisión.

Con relación a las atribuciones, además de eliminar expresamente la de llevar a cabo "la interpretación judicial de la Constitución", que comentamos en otro momento, la Ley de 1994 introduce importantes novedades en el ámbito del control de constitucionalidad, con relación a lo que disponía la Ley de 1993. Así, en el artículo 120, a), se especifica que el Tribunal Constitucional conoce y resuelve los asuntos de inconstitucionalidad de "leyes, decretos y cualquier género de resoluciones no judiciales". El calificativo de "no judiciales" (que se repite en el artículo 121, sobre los efectos de las sentencias del Alto Tribunal) es nuevo, puesto que en la Ley de 1993 no se especificaba nada.

Pero hay un cambio más importante en este artículo, y se refiere a la legitimación para interponer el recurso abstracto de inconstitucionalidad. Mientras que en la Ley declaratoria se exigia $1 / 3$ de Diputados o Senadores, el texto definitivo legitima a cualquier Diputado o Senador, individualmente, así como al Defensor del Pueblo. Llama la atención una modificación tan sustancial, que abre la posibilidad de que puedan plantearse multitud de recursos ante el Tribunal. Esta facultad individual, en función de cómo sea utilizada por los representantes populares, puede suponer un riesgo de acumulación de trabajos en el Tribunal, que podría repercutir en una mayor lentitud $y$, por tanto, menor eficacia, a la hora de resolver los asuntos.

Además, la Ley de 1994 añade una atribución a las previstas inicialmente, que es la de controlar "la constitucionalidad de tratados o convenios con Gobiernos extranjeros u organismos internacionales". 


\section{G) Modelos distintos de Consejo de la Judicatura}

El párrafo 5 del artículo 116 de la Constitución reformada dice lo mismo que se recogía en al artículo 119 de la Ley declaratoria de 1993: "El Consejo de la Judicatura es el órgano administrativo y disciplinario del Poder Judicial». Pero llama la atención que en la última frase del primer párrafo del mismo artículo se diga que «el Consejo de la Judicatura forma parte del Poder Judicial». Técnicamente no debe ser asi, puesto que se trata del órgano de autogobierno del Poder Judicial, pero no ejerce funciones jurisdiccionales.

Entre ambas leyes hay también un cambio sistemático: mientras que en la de 1993 se regulaba primero el Consejo de la Judicatura y después el Tribunal Constitucional, la de 1994 lo hace al revés, por lo que así ha quedado en la Constitución reformada.

El artículo 122 que se incluye en la Ley de Reforma (equivalente al 119 de la Ley de 1993) añade la posibilidad de nombrar como miembros del Consejo a abogados que hayan ejercido no necesariamente como tales, sino la docencia universitaria ${ }^{17}$. Además, introduce una modificación sustancial en el sistema de elección, puesto que los miembros deben ser elegidos por $2 / 3$ de los votos de los miembros presentes del Congreso Nacional, mientras que en la Ley de 1993 se exigian los 2/3 de los votos del total de miembros.

Por último, en el artículo 122, que enumera las atribuciones del Consejo de la Judicatura, se elimina una de ellas, que sí estaba prevista en la Ley de 1993. Se trata de la facultad de "procesar en vía disciplinaria a Magistrados de la Corte Suprema, Vocales superiores de Distrito, Jueces y funcionarios judiciales por faltas y contravenciones en el ejercicio de sus funciones, suspendiéndolos temporalmente por mayoría absoluta de votos del total de sus miembros y, en su caso,

17 Artículo 122. "l. El Consejo de la Judicatura es el órgano administrativo y disciplinario del Poder Judicial. Tiene su sede en la ciudad de Sucre.

II. EI Consejo es presidido por el Presidente de la Corte Suprema de Justicia y está integrado por cuatro miembros denominados consejeros de la Judicatura, con título de abogado en provisión nacional y con diez años de ejercicio idóneo de la profesión o la cátedra universitaria.

III. Los consejeros son designados por el Congreso Nacional por el voto de dos tercios de sus miembros presente. Desempeñan sus funciones por un periodo de diez años no pudiendo ser reelegidos sino pasado un tiempo igual al que hubiesen ejercido su mandato". 
encausándolos ante el Tribunal competente" (artículo 120, d) de la Ley de 1993).

Sorprende esta omisión, porque pienso que esa facultad es una concreción necesaria del ejercicio de la potestad disciplinaria que debe ejercer el Consejo de la Judicatura.

\section{H) Cambios relativos al Ministerio Público}

En el artículo 124 de la Constitución reformada no se incluye un párrafo que sí figuraba en la Ley declaratoria de 1993, que decia: «EI Ministerio Público goza de independencia funcional, administrativa $y$ autonomía de ejecución presupuestaria en el ejercicio de sus funciones". Además, como es habitual en otros órganos, la mayoría exigida para su elección se reduce. Mientras que en la Ley inicial se pedian 2/3 del total de miembros del Congreso, en el texto final sólo se exigen los $2 / 3$ de los miembros presentes.

\section{I) Modificaciones en la regulación del Defensor del Pueblo}

Además de la ya habitual diferencia de mayorías exigidas para su elección (2/3 de miembros presentes, o 2/3 del total de miembros del Congreso Nacional), se añade, en el texto incluido finalmente en la Constitución, la facultad de presentar el recurso de inconstitucionalidad. Por el contrario, se suprime el párrafo que se incluía en el artículo 129 que decia: "El Defensor del Pueblo tiene acceso libre e irrestricto a los medios de comunicación social del Estadon.

Asimismo, se limitan en el texto finalmente introducido en la Constitución los efectos de la negativa a dar información por parte de autoridades y funcionarios públicos. La Ley de 1993 decía que existía la obligación de dar esa información "en el plazo que el Defensor del Pueblo establezca, bajo pena de ser procesados como reos de atentado contra los derechos y garantías constitucionales". Sin embargo, el texto final dice: "En caso de no ser debidamente atendido en su solicitud, el Defensor deberá poner el hecho en conocimiento de las Cámaras legislativas».

Como puede deducirse, la eficacia de las actuaciones del Defensor del Pueblo con relación a la Administración Pública sería mucho mayor con el régimen inicialmente previsto. El texto vigente devalúa un tanto la posible eficacia de las reclamaciones que el Defensor del Pueblo pueda efectuar. 


\section{J) Cambios en relación con el Poder Judicial}

De modo acertado, la Ley de 1994 introduce una garantía ausente en la Ley de 1993. Se trata de prever un régimen básico de incompatibilidades para los que ocupan puestos de jueces o magistrados: «EI ejercicio de la judicatura es incompatible con toda actividad pública y privada remunerada, con excepción de la Cátedra Universitaria" (artículo 116, párrafo 9 ).

Además, la Ley de Reforma añade, en el artículo 117, que la sede de la Corte Suprema de Justicia está en la ciudad de Sucre, y que el Presidente de dicha Corte se elige por $2 / 3$ de los votos del total de sus miembros. Por su parte, en el artículo 118 se suprimen, con respecto a la Ley de 1993, la atribución de "dirigir" al Poder Judicial, y la de "decidir las cuestiones de límites que se suscitaren entre los Departamentos, Provincias, Secciones y Cantones". Parece lógico que la función de dirigir al poder Judicial corresponde al Consejo de la Judicatura, y no tiene sentido atribuírsela a la propia Corte Suprema, aunque sí es el órgano jurisdiccional jerárquicamente superior, como se dice al inicio del artículo 117.

\section{K) Otros cambios}

El resto de las modificaciones son de menor importancia. Por ejemplo, en la elección de Alcalde regulada en el artículo 200, se reducen de 3 a 2 el número de las votaciones si no hay mayoría absoluta. Asimismo, el texto definitivo suprime el principio de proporcionalidad para determinar el número de concejales atribuidos a cada grupo político. En el artículo 220 se añade la inscripción obligatoria para poder ejercer el derecho al sufragio.

Finalmente, el artículo 203 que se incluye en la Constitución es bastante más escueto que el que figuraba en la Ley de 1993, donde se preveían una serie de medidas que deberían favorecer la descentralización también en el ámbito municipal, y los requisitos para que las comunidades fuesen reconocidas como Municipios.

En definitiva, si la ley declaratoria se considera ya proyecto de reforma y, por tanto, vincula a las nuevas Cámaras, es evidente que la reforma de 1994 no ha respetado el procedimiento previsto constitucionalmente. Cuestión distinta sería que la ley fuese simplemente una declaración de la necesidad de reformar la Constitución. Entonces las nuevas Cámaras tendrían las manos libres para actuar. En todo caso, 
se echa de menos que todo el procedimiento de reforma constitucional culmine con la ratificación popular de lo que sus representantes elaboren, a través de un referéndum que debería de preverse como punto final del cambio constitucional.

\section{LAS LEYES INTERPRETATIVAS: ¿REFORMAS ENCUBIERTAS?}

En la parte cuarta de la Constitución boliviana, dedicada a la "Primacía y Reforma de la Constitución" se incluyen, además de los articulos citados, otros dos, uno sobre las leyes interpretativas y otro que contiene la tradicional cláusula derogatoria. El artículo 234 establece: "Es facultad del Congreso dictar leyes interpretativas de la Constitución. Estas leyes requieren dos tercios de votos para su aprobación y no pueden ser vetadas por el Presidente de la República».

La propia ubicación de este artículo junto con el instituto de la Reforma, $y$ algunas de las especificidades del procedimiento de aprobación de este tipo de leyes, parecen indicar que, en realidad, a través de las leyes interpretativas, se está desarrollando por parte del Poder Legislativo una función que debe corresponder al Poder Constituyente, como es la de reformar, de modo en este caso más o menos indirecto, el propio contenido de la Constitución. Resulta bastante sorprendente esta norma, que entraña riesgos evidentes en cualquier sistema político ${ }^{18}$.

A esta regulación se une el hecho de que, mientras que en la Ley declarativa de la necesidad de la Reforma se hablaba de que el Tribunal Constitucional es el intérprete judicial de la Constitución (art. 121), la mención a esta función desaparece en el texto definitivo de la Reforma. La intencionalidad es clara, máxime si tenemos en cuenta lo afirmado en ese tiempo por el propio Miguel Harb, que criticaba lo dispuesto en el art. 121 por entender que, puesto que el art. 234 otorga al Congreso la facultad de dictar leyes interpretativas de la Constitución, no cabe otra interpretación distinta de ésta ${ }^{19}$. Pero lo que llama la aten-

${ }_{18}$ Las contradicciones de la existencia de dos tipos de interpretaciones intentan ser salvadas en el trabajo de AsBúN, J., "Control Constitucional en Bolivia: Evolución y Perspectivas", en Jurisdicción Constitucional, Academia Boliviana de Estudios Constitucionales, Santa Cruz, 2000, págs. 89 y 90.

19 Miguel HARB, B., "Intervención», en Documentos de trabajo para la Reforma Constitucional, Consejo Nacional de la Reforma y Modernización del Poder Judicial, 1994, pág. 15. 
ción es que este autor se limite a señalar una hipotética contradicción, sin denunciar el grave error de concepto que supone retirar al Tribunal Constitucional una facultad básica entre las que son sus funciones tradicionales y esenciales.

El máximo órgano (aunque no el único) facultado para interpretar la Constitución es el Tribunal Constitucional. Además, todos los demás órganos jurisdiccionales deben aplicar la Constitución, lo cual exige en muchos casos una labor interpretadora, que en todo caso debe ajustarse a los criterios interpretativos del Alto Tribunal. Pero el Poder Legislativo carece de competencias en este ámbito. Es contradictorio con el esquema de frenos y contrapesos, de equilibrio entre los poderes de cualquier sistema político democrático. Diga lo que diga la Constitución, si ésta tiene pretensión de eficacia y de normatividad, debe ser interpretada por los tribunales $y$, especialmente, por el Tribunal Constitucional ${ }^{20}$.

Algún autor ha intentado hacer compatible la labor interpretadora del Tribunal Constitucional con la existencia de las leyes interpretativas, señalando que "la función de interpretación que realizan es distinta y a la vez complementaria. El Legislativo, como representante de la voluntad popular, dicta una ley interpretando algún contenido confuso o contradictorio de la Constitución, mientras que el Tribunal controla si esa ley responde a los presupuestos constitucionales $y$, en consecuencia, si guarda la debida coherencia con la misma, pero no puede crear el sentido de ella, dado que es un legislador negativo" ${ }^{21}$.

Se comprende el interés por hacer compatible la figura de las leyes interpretativas con la labor del Tribunal Constitucional, pero creo que no es posible llegar a esta conclusión. El Alto Tribunal no sólo interpreta la Constitución, sino que debe también interpretar las leyes, en el sentido de que deberá determinar, en el caso de existan distintas

20 Sin contradecir expresamente lo que dice Miguel Harb, Fernández Segado parece hacer compatibles las dos tareas: la de elaboración de leves interpretativas por el Congreso, y la propia interpretación que haga el Tribunal. En mi opinión, esta compatibilidad de funciones entre Legislativo y Tribunal Constitucional no puede existir, por la confusión a la que puede dar lugar. Otra cosa es que el poder Legislativo apruebe leyes que, sin ser contrarias a la Constitución, vincularán también al Tribunal Constitucional. Cfr. Fernández Segado, F., "La jurisdicción constitucional en la Reforma de la Constitución de Bolivia de 1994», en Fernández Segado (coord.), La jurisdicción constitucional en lberoamérica, op. cit., pág. 369.

21 Asbún, J., "Control Constitucional en Bolivia: Evolución y Perspectivas", en Jurisdicción Constitucional, Academia Boliviana de Estudios Constitucionales, Santa Cruz, 2000, pág. 90. 
posibilidades, cuál debe ser la correcta interpretación que sea conforme con la Constitución. Por lo tanto, además de poder actuar como legislador negativo, el Tribunal puede aclarar, en caso de duda, cómo debe entenderse el contenido una ley, de manera que la aplicación de ésta no entre en conflicto con la Constitución.

Por lo que se refiere a la interpretación auténtica de la Constitución, entra dentro también de las funciones del Tribunal Constitucional. Podría objetarse a esta idea que, de lo que se trataría con las leyes interpretativas es de aclarar la Constitución en aquellos puntos en los que no llegue a concretar de modo expreso su contenido. Pero, en este caso, caben dos opciones:

a) Si el texto constitucional es claro, y simplemente no se extiende en las consecuencias que de su propio contenido se derivan, será el Tribunal Constitucional quien debe fijar estas consecuencias, aplicadas a cada caso concreto. Cuando el Poder Constituyente desea que sea el Legislativo quien complete la regulación de un determinado aspecto que no se desarrolla en la Constitución, lo que hace es remitir expresamente esa regulación a la actuación del Parlamento, aprobando las leyes que sean necesarias para regular una materia. Pero si no hay remisión expresa, el Parlamento lo único que puede hacer es legislar respetando el contenido de la Constitución. Quien debe juzgar si ese contenido es o no respetado es el Tribunal Constitucional, máximo intérprete de la Norma Suprema.

b) Si el texto constitucional contiene una redacción confusa, difícilmente interpretable, lo que debe acometerse abiertamente es una Reforma constitucional. No se pueden establecer mecanismos modificadores de la Constitución a través de vías opacas, como puede ser la de las leyes interpretativas. No puede "aclararse" lo que dice la Constitución en una norma de rango inferior. ¿Dónde están en este caso las garantías de supremacia de la Norma constitucional? Parece más bien que las leyes interpretativas son un ataque al principio de supremacía constitucional. El procedimiento de aprobación, con la exigencia de dos tercios de los votos (¿de quiénes? ¿del total o de los presentes?) en el Congreso, y la prohibición de veto por parte del Presidente, parece un reconocimiento tácito de que este tipo de leyes puede suponer una reforma encubierta de la Constitución.

En todo caso, el texto del la Ley del Tribunal Constitucional parece confirmar, en el artículo 4, lo que estamos sosteniendo, puesto que 
dice: «En caso excepcional de que una ley, decreto, o cualquier género de resolución admita diferentes interpretaciones, el Tribunal Constitucional en resguardo del principio de conservación de la norma adoptará la interpretación que, concuerde con la Constitución.

Los tribunales, jueces y autoridades aplicarán a sus decisiones la interpretación adoptada por el Tribunal Constitucional» ${ }^{22}$.

Aunque se hable de "caso excepcional", se está reconociendo algo que es evidente, como es la capacidad de interpretación que el Tribunal tiene, así como el carácter vinculante de ésta, no sólo para jueces y tribunales, sino para todas las autoridades, entre las que debe incluirse el propio legislador.

El último artículo de la Constitución, el 235, contiene una cláusula derogatoria que habilita a los jueces ordinarios para inaplicar una norma preconstitucional, en el caso de que aprecien su contradicción con el texto de la Constitución. En este supuesto, por lo tanto, no se requiere acudir al Tribunal Constitucional para que dictamine la inconstitucionalidad de una norma, sino que cualquier órgano judicial, que como hemos dicho debe aplicar de modo eficaz la Norma Suprema, puede considerar inconstitucional una norma preconstitucional, y no aplicarla al caso concreto. En este sentido, el modelo de control concentrado de constitucionalidad ha ido evolucionando, acercándose en algunos aspectos -como en éste que estamos comentando- al de control difuso que se sigue en Estados Unidos.

\section{EL TRIBUNAL CONSTITUCIONAL}

Uno de las principales novedades de la Constitución boliviana de 1994 es la creación, por primera vez en Bolivia, de un Tribunal Constitucional. Con ello se pasaba de un teórico sistema de control difuso de la constitucionalidad a uno de control concentrado.

Hasta esta reforma, y fijándonos en concreto en la Constitución de 1967, podemos observar cómo, en el plano teórico, existía en Bolivia un modelo de control difuso de constitucionalidad ${ }^{23}$ que correspondía, en última instancia, a la Corte Suprema de Justicia. Pero, en la práctica, este control no se llevó a cabo, pues la Corte no hizo uso ade-

22 Ley del Tribunal Constitucional, número 1836, de 1 de abril de 1998.

23 Galindo DeCKer, H., Tribunal Constitucional, Editorial Jurídica Zegada, La Paz, 1994, págs. 25 y ss. 
cuado de esta atribución. Esta situación ha llevado a algunos autores a dudar incluso de la sinceridad del propio constituyente cuando elaboró la Constitución de $1967^{24}$.

Como decimos, la situación cambió con la reforma de 1994. No fue fácil, sin embargo, la incorporación del Tribunal Constitucional. Tanto en los debates de la Ley declaratoria de la necesidad de la Reforma como en el propio texto de la Reforma se dieron numerosos argumentos a favor $y$ en contra del control difuso y del concentrado ${ }^{25}$. EI debate se trasladó a la opinión pública, entrando en liza incluso la propia Corte Suprema, que no quería perder sus competencias y recelaba del nuevo órgano constitucional ${ }^{26}$.

Finalmente, la regulación del Tribunal Constitucional quedó ubicada dentro de la Parte Segunda de la Constitución ("El Estado boliviano»), Título Tercero («Poder Judicial»), Capítulo Segundo. Además, viene a completar la regulación la Ley número 1836, de 1 de abril de 1998, del Tribunal Constitucional. Sin duda, la creación del Tribunal Constitucional fue uno de los aspectos más positivos de la Reforma constitucional boliviana, como se puso de relieve por los sectores más autorizados de la doctrina ${ }^{27}$, y como ha demostrado luego la práctica del nuevo órgano constitucional boliviano.

Lo primero que llama la atención es que el Tribunal Constitucional se integra en el Poder Judicial. No ocurre lo mismo en la mayoría de las constituciones de los estados democráticos contemporáneos. EI artículo 116 es muy claro en su redacción: «el Poder Judicial se ejerce - por la Corte Suprema de Justicia de la Nación, el Tribunal Constitucional, las Cortes Superiores de Distrito, ...n. El Tribunal Constitucional no figura ni siquiera en primer lugar en esta relación de órganos que componen el Poder Judicial. Más adelante (art. 116.4) se encomienda especificamente al Tribunal Constitucional el control de cons-

24 Asbún, J., Análisis juridico-político de la reforma constitucional, Universidad Privada de Santa Cruz de la Sierra, Santa Cruz, 1994, págs. 28-29.

${ }_{25}$ Pueden verse los argumentos principales de estos debates en GaLINDO Decker, H., Tribunal Constitucional, op. cit., págs. 51 y ss.; Galindo de Ugarte, M., ¿Tribunal Constitucional o Corte Suprema? Una contribución al debate, Fundación Milenio, La Paz, 1994, págs. 67 y ss.

${ }_{26}$ Pueden consultarse más detalles en Galindo DeCKER, H., Tribunal Constitucional, op. cit., págs. 85 y ss.; GALINDO DE UGARTE, M., ¿Tribunal Constitucional o Corte Suprema? Una contribución al debate, op. cit., págs. 11 y ss.

${ }_{27}$ Cfr., entre otros, AsBún, J., Análisis jurídico-político de la reforma constitucional, op. cit., págs. 27 y ss.; URcullo Reyes, J., Proceso democrático, situación jurídica y reforma constitucional en Bolivia, Urquizo, La Paz, 1993, págs. 167 y ss. 
titucionalidad, sin mencionar nada sobre la protección de derechos fundamentales o la resolución de conflictos interorgánicos o competenciales. Sin embargo, como se verá, las atribuciones del Alto Tribunal son bastantes más.

Quizá lo más lógico hubiese sido situar al Tribunal Constitucional en el primer lugar de esa relación, o incluso fuera del orden jerárquico establecido entre los distintos órganos jurisdiccionales. La diferencia entre los tribunales ordinarios y el Constitucional es evidente, y la reconoce la misma Constitución. Mientras que "los magistrados y los jueces son independientes en la administración de justicia y no están sometidos sino a la Constitución y la ley" (art. 116.6), el Tribunal Constitucional es, por supuesto, independiente, pero "está sometido sólo a la Constitución» (art. 119.1).

\section{A) Composición y designación de los miembros del Tribunal}

El Tribunal Constitucional está integrado por cinco magistrados, organizados en una sola sala, designados por el Congreso Nacional por dos tercios de los votos de los miembros presentes (art. 119.2). De nuevo nos encontramos con esta peculiar manera de exigir una mayoría, tomando como base no el total de miembros de la Cámara, sino sólo los presentes. Sin embargo, para la elección de Presidente del Tribunal Constitucional sí se exige la elección por dos tercios del total de magistrados, es decir, por cuatro de los cinco miembros.

Son elegidos para un período de diez años, que no son prorrogables de modo inmediato, pero sin embargo pueden ser reelegidos una vez transcurrido un lapso de tiempo igual al que hubiesen pasado en el ejercicio de su cargo (art. 119.5).

Por lo que se refiere a los requisitos para ser Magistrado del Tribunal, son los mismos que para formar parte de la Corte Suprema de Justicia. Así lo establece el artículo 119.4, remitiéndose al 117.3. Éste, a su vez, se remite a los artículos que establecen las condiciones requeridas para ser diputado (art. 61) y senador (art. 64), con la exclusión de los apartados 2 y 4 del artículo 61. En definitiva, los requisitos son:

a) tener al menos 35 años de edad (art. 64),

b) ser boliviano de origen y haber cumplido los deberes militares (art. 61.1),

c) estar inscrito en el Registro Electoral (art. 61.3), 
d) no haber sido condenado a pena corporal, salvo rehabilitación concedida por el Senado; ni tener pliegos de cargo o auto de culpa en fase de ejecución, ni estar comprendido en los casos de exclusión y de incompatibilidad establecidos por ley (art. 61.5),

e) tener título de Abogado en Provisión Nacional (art. 117.3),

f) haber ejercido con idoneidad la judicatura, la profesión o la cátedra universitaria por lo menos durante diez años (art. 117.3).

Asimismo, el enjuiciamiento penal de los miembros del Tribunal Constitucional se rige por las mismas normas establecidas para los ministros de la Corte Suprema (art. 119.6). Es decir, que pueden ser acusados por la Cámara de Diputados ante el Senado, por delitos cometidos en el ejercicio de sus funciones (art. 62.3), y el Senado, una vez que tenga conocimiento de dicha acusación, juzgará en única instancia y tomará la decisión que estime oportuna, por una mayoría de dos tercios de los miembros presentes (art. 66.1).

\section{B) Atribuciones del Tribunal Constitucional}

Es el artículo 120 de la Constitución el que recoge las competencias de este Tribunal. Apenas hace unas líneas decíamos que, en el artículo 116, el primero del Título dedicado al Poder Judicial, sólo se especificaba el control de constitucionalidad como función del Tribunal. Sin embargo, son bastantes más. Lo que ocurre es que, en el caso del control de constitucionalidad, se constituye en juez único, mientras que en los otros supuestos no siempre es asi.

a) En primer lugar, al Tribunal Constitucional corresponde el control de constitucionalidad de "leyes ${ }^{28}$, decretos y cualquier género de resoluciones no judiciales" (art. 120.1) y de tratados o convenios internacionales (art. 120.9). Llama la atención que el objeto del control pueda ser tan amplio. Lo normal es que fuesen las leyes o normas con rango legal, pero no las resoluciones, del tipo que sean. El control puede ser abstracto o concreto, como se deduce del texto del art. 120.1. Volveremos más tarde sobre ello.

28 Hasta 1994, esta competencia correspondía teóricamente a la Corte Suprema de Justicia, aunque en la práctica no se utilizó de modo adecuado. Estaba prevista en el artículo 127.5 de la Constitución de 1967. 
b) También es competencia del Tribunal Constitucional resolver los conflictos entre los poderes públicos, la Corte Nacional Electoral, los Departamentos y Municipios (art. 120.2).

c) Conoce también las impugnaciones del Poder Ejecutivo contra las resoluciones de las Cámaras, Prefecturas y Municipios (art. 120.3).

d) Asimismo, los recursos contra tributos, impuestos, etc., creados, modificados o suprimidos en contra de lo dispuesto en la Constitución (art. 120.4); los recursos contra resoluciones del Poder Legislativo o una de sus Cámaras que afecten a uno o más derechos o garantías concretas, cualesquiera que sean las personas afectadas (art. 120.5); los recursos de nulidad provocada por usurpación de funciones o por actuaciones no amparadas en la ley (art. 120.6, en relación con el 31).

e) Al Alto Tribunal compete la revisión de los recursos de amparo constitucional y "habeas corpus", regulados en los artículos 18 y 19 de la Constitución (art. 120.7).

f) Debe también resolver las consultas que le plantee el presidente de la República, el del Congreso y el de la Corte Suprema, sobre la constitucionalidad de proyectos de ley, decretos o resoluciones, o de leyes, decretos y resoluciones aplicables a un caso concreto. La consulta es vinculante para el órgano que la efectúa (art. 120.8). Aquí estarian incluidos los supuestos de control previo (si son proyectos de ley) y sucesivo (si son leyes).

g) Por último, el Tribunal puede revisar los procedimientos de reforma constitucional (art. 120.10), pero a sensu contrario, no puede juzgar sobre su contenido. Así lo dispone además la Ley n. 1836 de 1 de abril de 1998, del Tribunal Constitucional, en su artículo 117: "El control se circunscribirá a la observancia de las formalidades de procedimiento de reforma (...), sin que en ningún caso se ingrese en el análisis del contenido material de la reforman.

Decíamos que puede hablarse en Bolivia de dos tipos de control de constitucionalidad, aunque no se haga mención expresa de ello en el texto de la Carta Magna. El artículo 120.1 dispone que, si la "acción» de inconstitucionalidad es de "carácter abstracto y remedial, sólo podrán interponerla el presidente de la República, o cualquier Senador o Diputado, el Fiscal General de la República o el Defensor del Pueblo». Por lo tanto, aqui estamos hablando de un control abstracto de constitucionalidad, para el cual la legitimación es bastante amplia, por cierto. 
El control concreto lo deducimos de lo establecido por el artículo 120.8 , ya citado. El Presidente de la Corte Suprema de Justicia puede plantear la consulta de constitucionalidad al Tribunal, con relación a leyes, decretos o resoluciones aplicables al caso concreto.

La cuestión se aclara más si acudimos a la Ley del Tribunal Constitucional, que desarrolla estos preceptos de la Norma Suprema. En su artículo 7 habla de las "acciones o demandas abstractas o directas de inconstitucionalidad de leyes, decretos y resoluciones de cumplimiento general", y de "recursos incidentales de constitucionalidad". Los dos tipos de acciones de inconstitucionalidad son expresamente mencionados en el artículo 53 de la Ley del Tribunal Constitucional: puede proceder la acción como "demanda abstracta de inconstitucionalidad", o como "recurso incidental de constitucionalidad vinculado a un proceso judicial o administrativon. El procedimiento para plantear la primera se regula en los artículos 54 a 58 de la Ley, y el recurso incidental en los artículos 59 a 67.

Así como la legitimación para la acción abstracta está prevista en la propia Constitución, y la Ley se limita a transcribirla, el recurso incidental de inconstitucionalidad procederá, según el artículo 59 de la Ley, "en los procesos judiciales y administrativos cuya decisión dependa de la constitucionalidad o inconstitucionalidad de una ley, decreto o cualquier género de resolución un judicial aplicable a aquellos procesos. Este recurso será promovido por el juez, tribunal o autoridad administrativa, de oficio o a instancia de parte".

Cabe llamar la atención sobre el hecho de que la admisión del recurso indirecto o incidental de inconstitucionalidad no suspenderá la tramitación del proceso, mientras se pronuncie el Tribunal Constitucional, salvo el caso de ser presentado en recurso de casación o jerárquico (art. 63).

Puede existir también, además de este control a posteriori, el control previo de constitucionalidad. En el mismo artículo 120.8 dispone que el presidente de la República, el del Congreso y el de la Corte Suprema pueden elevar consultas al Tribunal Constitucional sobre la constitucionalidad de proyectos de ley, decretos o resoluciones.

\section{LOS DERECHOS FUNDAMENTALES $Y$ EL RECURSO DE AMPARO}

Finalmente, aunque sin entrar en demasiado detalle en la regulación especifica de cada derecho fundamental, me gustaría hacer una 
serie de observaciones básicamente de tipo sistemático, con relación a la incorporación de los derechos humanos a la Constitución boliviana, y al régimen de garantías.

El artículo 19 de la Constitución y el 94 de la Ley del Tribunal Constitucional establecen que el recurso de amparo puede presentarse ante todo acto ilegal, resolución, acto $u$ omisión indebida de autoridad o funcionario, siempre que no hubiere otro medio o recurso para la protección inmediata de los derechos y garantías reconocidos en la Constitución y en las leyes. La lesión, por tanto, puede provenir tanto de los poderes públicos como de particulares. El problema se plantea cuando intentamos individuar los derechos y garantías protegidos, puesto que no se especifica ningún apartado concreto de la Constitución. Además, el artículo 35 de la Norma Suprema introduce una cláusula abierta a cualquier derecho no reconocido en la Constitución de modo expreso, al afirmar que: "Las declaraciones, derechos y garantías que proclaman esta Constitución no serán entendidos como negación de otros derechos y garantías no enunciados que nacen de la soberanía del pueblo y de la forma republicana de gobierno". O sea, que otros derechos reconocidos por ley, o por tratado internacional, podrían ser objeto asimismo de recurso de amparo.

Junto a ello, sin embargo, encontramos que en la Constitución existen dos títulos (el I y II de la Parte Primera, "La persona como miembro del Estado"), cuyas rúbricas dicen: "Derechos y deberes fundamentales de la persona" y "Garantías de la persona". ¿Podría entonces interpretarse el artículo 19 en el sentido de que sólo los derechos aquí incluidos estarían amparados? Parece que no, por la cláusula ya comentada del artículo 35 . Pero es que además, un análisis del contenido de esos dos títulos revela que no puede ser así.

En el Título Primero, sobre Derechos y Deberes fundamentales de la persona, se incluye la prohibición de la esclavitud y cualquier tipo de servidumbre (art. 5), el derecho a la igualdad (art. 6), y un elenco de derechos (art. 7) y deberes (art. 8) que simplemente consiste en una enumeración, sin entrar en ningún tipo de desarrollo, por lo que muchos de ellos necesitarán que éste se produzca por vía legal o reglamentaria. He aqui un primer punto delicado: no existe ninguna reserva expresa de ley para la regulación de estos derechos. El artículo 7 dice de modo explícito: "Toda persona tiene los siguientes derechos fundamentales, conforme a las leyes que reglamenten su ejercicio", pero no se dice si esas leyes pueden ser a su vez desarrolladas por otras normas de rango inferior, o no se señala expresamente que "sólo podrán ser regulados por ley", como quizá debería haberse dicho. En el caso 
de los deberes ni siquiera se hace esa mención a las leyes, es decir, que pueden regularse por cualquier tipo de norma.

En el Título Segundo, sobre las Garantías, encontramos, además del Habeas Corpus (art. 18), el recurso de amparo (art. 19), y algunos derechos procesales, que hacen honor a la rúbrica del Título; pero también se hallan en ese Título otros derechos fundamentales (o que al menos deberían considerarse así) que, o bien tienen doble naturaleza de derecho y garantía, o simplemente no son garantías. Así, por un lado tenemos el derecho de libertad y las posibles limitaciones, duración máxima de la detención preventiva (art. 9), la necesidad de intervención judicial en las detenciones y para el ingreso en prisión (art. 11), la prohibición de tribunales especiales (art. 14), la presunción de inocencia, derecho de defensa y asistencia de un abogado (art. 16). Pero, junto a ellos, encontramos la prohibición de torturas, tratos inhumanos o degradantes (art. 12), que es también un derecho fundamental, como lo son la inviolabilidad de las comunicaciones (art. 20), la inviolabilidad de domicilio, en la que se hace una curiosa distinción entre la noche $y$ el día ${ }^{29}$ (art. 21), la propiedad privada, aunque sometida al interés general (art. 22), algunos artículos sobre limitaciones de derechos de los extranjeros, y otras disposiciones que entran quizá en detalles innecesarios para una Constitución, como cuestiones relativas a los Bienes de la Iglesia y las órdenes religiosas (art. 28).

Parece, por tanto, que en este Título hay también derechos y no sólo garantías, $\vee$ que estos derechos deben entenderse como protegidos por el recurso de amparo. El artículo 35 es el último de este Título, e introduce la cláusula de apertura a la que ya se ha hecho referencia.

No parece que los derechos recogidos en los títulos mencionados sean todos los que deben gozar del máximo nivel de protección. $Y$, al contrario, hay otros artículos que podrían haberse insertado en otros apartados, porque no contienen ni derechos, ni garantías que deban considerarse como fundamentales. Los derechos que se echan de menos podemos encontrarlos en otros artículos de la Constitución. Veámoslo.

En el artículo 40 se encuentra el derecho de acceso a funciones públicas $y$ el derecho al sufragio activo $y$ pasivo, también reconocido

29 "Toda casa es un asilo inviolable; de noche no se podrá entrar en ella sin consentimiento del que la habita, y de día sólo se franqueará la entrada a requisición, escrita y motivada de autoridad competente, salvo el caso de delito in fragantis. 
en los artículos 219 y 220 . Otros derechos que están dispersos por la Constitución son: el derecho al trabajo y el deber de trabajar (art. 156); el derecho a la libre asociación patronal, a la libre sindicación y a la huelga (art. 159); algunas limitaciones al derecho de propiedad (art. 167); los derechos sociales, económicos y culturales de las comunidades indígenas (art. 171); los derechos educativos (art. 177), la libertad de enseñanza religiosa (art. 182); la autonomía universitaria (art. 185); el derecho al matrimonio y la protección de la familia (arts. 193 y 194); la igualdad de los hijos con independencia de su origen (art. 195).

Además, el régimen de suspensión de los derechos se regula dentro del Capítulo IV ("Conservación del orden público"), del Título II ("Poder Ejecutivo»), de manera por cierto muy confusa (art. 112.3 y 4) y permitiendo la censura de las comunicaciones (art. 112.5), aunque con la garantía del control del Congreso en todo el proceso ${ }^{30}$.

En definitiva, parece aconsejable acometer una reforma de la regulación de los Derechos Fundamentales, estableciendo una sistemática más clara, algunas garantías más, sobre todo la de reserva de ley $y$ las que se refieren al régimen de suspensión de los derechos. Junto a ello, sería conveniente agrupar todos los derechos que se consideren fundamentales en un solo apartado, aunque luego se desarrollen con más amplitud en otros, como podría ocurrir con los derechos laborales, que podrían incluirse tanto en el apartado de derechos fun-

\section{0 "Artículo 112. (...)}

3. Las garantias y los derechos que consagra esta Constitución no quedarán suspensos de hecho $y$ en general con la sola declaratoria del Estado de Sitio; pero podrán serlo respecto de señaladas personas fundadamente sindicadas de tramar contra el orden público, de acuerdo a lo que establecen los siguientes párrafos.

4. Podrá la autoridad legítima expedir órdenes de comparendo o arresto contra los sindicados, pero en el plazo máximo de cuarenta y ocho horas los pondrá a disposición del juez competente, a quien pasará los documentos que hubiesen motivado el arresto. Si la conservación del orden público exigiese el alejamiento de los sindicados, podrá ordenarse su confinamiento a una capital de departamento o de provincia que no sea malsana. Queda prohibido el destierro por motivos políticos; pero al confinado, perseguido o arrestado por estos motivos, que pida pasaporte para el exterior, no podrá serle negado por causa alguna debiendo las autoridades otorgarle las garantías necesarias al efecto.

5. Los ejecutores de órdenes que violen estas garantías podrán ser enjuiciados en cualquier tiempo, pasado que sea el Estado de Sitio, como reos de atentado contra las garantias constitucionales, sin que les favorezca la excusa de haber cumplido órdenes superiores.

En caso de guerra internacional, podrá establecerse censura sobre la correspondencia y todo medio de publicación". 
damentales como en el que se refiera al régimen económico. Además, podría ser oportuno señalar de modo claro qué derechos son amparables y cuáles no. La opción actual por considerar todos los derechos como susceptibles de recurso probablemente no sea la mejor, a menos que se distingan dos tipos de amparo: aquél que puede llegar ante el Tribunal Constitucional, y aquél que se debe resolver exclusivamente por los Tribunales ordinarios. 